\title{
Fourier transform infrared spectroscopic studies of diabetic rat heart crude membranes
}

\author{
Feride Severcan $^{\mathrm{a}, *}$, Neşe Kaptan ${ }^{\mathrm{a}}$ and Belma Turan ${ }^{\mathrm{b}}$ \\ ${ }^{a}$ Department of Biology, Middle East Technical University, 06531, Ankara, Turkey \\ ${ }^{\mathrm{b}}$ Department of Biophysics, Faculty of Medicine, Ankara University, Ankara, Turkey
}

\begin{abstract}
Application of mid infrared spectroscopy in diabetic tissues will be presented which highlight the promise of this technique in medical research. Examples presented mainly will focus on diabetic rat heart crude membranes. Diabetes mellitus (DM) was induced in rats by streptozotocin (STZ) injection that is one of the most popular experimental models for the study of type I diabetes. The shift in the peak positions, bandwidths and the intensity of the bands in FTIR spectra were analyzed to have valuable structural and functional information, which may have diagnostic value. In the diabetic membranes significant increase was observed in lipid order and lipids concentration. While the concentration of saturated lipids increases, the concentration of unsaturated lipids decreases. In addition, broadening of the amide I bands and the appearance of the new band around $1640 \mathrm{~cm}^{-1}$ together with the decrease in the amide I to amide II ratio indicate the structural changes occurring in proteins of diabetic membranes. A dramatic increase in oligosaccarite band $\left(1042 \mathrm{~cm}^{-1}\right)$ and a decrease in olefinic stretching band $\left(3012 \mathrm{~cm}^{-1}\right)$, were also observed.
\end{abstract}

Keywords: Diabetes, heart membrane, FTIR

\section{Introduction}

Diabetes mellitus is a heterogenous multi-organ disorder that can effect various systems of the human body. It has been known that diabetic patients have a tendency towards cardiovascular system disorders, including congestive heart insufficiency, hypertension, arteriosclerosis, micro and macro angiopathy and together with these, various smooth muscle functions have been negatively affected by this disease [1-8]. Disorders also include musculoskeletal abnormalities such as diminished bone formation, bone healing retardation and osteoporosis [9-11]. Although functional disorders of these organs have been determined both clinically and experimentally, the mechanisms behind these pathologies have not been completely understood yet. There are conflicting results on the effect of diabetes on membrane fluidity [12-16]. The other conflicting results appear in the analysis of $3012 \mathrm{~cm}^{-1}$ bands in diabetic tissues. This band arises from the olefinic $=\mathrm{CH}$ stretching vibrations which is used as an indication of peroxidation in the system. The behaviour of this band in terms of intensity changes due to diabetes is uncertain yet $[17,18]$.

Several studies including ours have used streptozotocin (STZ) to induce experimental diabetes, which is well-established model in the rat $[10,12,13,19]$. Streptozotosin impairs the function of pancreatic beta cells, thereby prevents the secretion of insulin. In the present study Fourier Transform Infrared (FTIR) spectroscopy was used to obtain detailed information about the effects of diabetes on structure, function and composition of rat crude heart membranes at molecular level. FTIR spectroscopy possesses several advantages for the study of biological tissues and membranes. It does not require the use of probe molecules. The method directly monitors specific functional molecules groups in the system.

\footnotetext{
${ }^{*}$ Corresponding author. Tel.: +90 312 2105166; Fax: +90 312 2101289; E-mail: feride@ metu.edu.tr.
} 


\section{Materials and methods}

\subsection{Reagent}

Streptozotosin and $\mathrm{KBr}$ and all other chemicals were purchased from Sigma Company.

\subsection{Animals and feeding}

17 Wistar rats of both sex (200-250 mg) were divided into two different groups, control (5 rats) and diabetic (12 rats). Animals were housed at a density two or three per cage, in a room that was maintained at temperature of $22 \pm 1{ }^{\circ} \mathrm{C}$ on a 12 -h light/dark cycle. They were provided with food and water at libitum until the experimentation. Rats were made diabetic by injection of a single i.p. dose of STZ (50 mg/kg body weight) dissolved in $0.05 \mathrm{M}$ citrate buffer ( $\mathrm{pH} 4.5$ ). Control animals were injected with citrate buffer alone. By the end of the first week after injection tail vein blood glucose was measured in all animals. Any streptozotin-threated rat having blood glucose level less than 2 times of control value was excluded from further study. At the end of 5th week all animals were anaesthetized with $30 \mathrm{mg} / \mathrm{kg}$ pertobarbital and then sacrified by opening their chest. All tissues were stored frozen $\left(-80^{\circ} \mathrm{C}\right)$ until analysis.

\subsection{Crude membrane preparation for FTIR analysis}

After removal of excess fatty and connective tissues, the heart tissue of each animal was washed in cold water. In the next step the samples was weight and ice-cold homogenization buffer (Appendix) was added $(1: 3 \mathrm{~g} / \mathrm{v})$. Homogenization was done with a T18 Turrax for $3 \times 20 \mathrm{sec}$. The homogenized sample was centrifuged at $1000 \mathrm{~g}$ for $10 \mathrm{~min}$. Supernatants obtained from previous step was centrifuged again in ultracentrifuge at $125000 \mathrm{~g}$ for $1 \mathrm{~h}$. Finally pellets, which will be used for FTIR study, were taken and placed $1 \mathrm{ml}$ alidouts.

\subsection{FTIR spectroscopy and spectral analysis}

Infrared spectra were obtained using a Bomem 157 FTIR Spectrometer (MB Series, Canada). The sample compartment was continuously purged with dry air to minimize water vapor and carbon dioxide interference. Spectra of membrane samples and thin sliced were recorded in the 4000-1000 $\mathrm{cm}^{-1}$ region with $\mathrm{CaF}_{2}$ window using $12 \mu \mathrm{m}$ path length. Interferograms were accumulated for 200 scans at $4 \mathrm{~cm}^{-1}$ resolution. All spectra were recorded at $25^{\circ} \mathrm{C}$ and the Grace-Specac temperature controller unit was used for temperature regulation. Bomem Easy and Grams/32 software were used for all FTIR data manipulations.

\subsection{Statistics}

The results were expressed as mean \pm standard deviation (SD). Data were analysed statistically by using student's $t$-test and the $\mathrm{p}$ values less than 0.05 were considered statistically significant.

\section{Results and discussion}

Strong water absorption located at $3500-3000 \mathrm{~cm}^{-1}$ and $1700-1600 \mathrm{~cm}^{-1}$ disturbs main lipid and protein bands of interest in this study, for this reason, the water signals should digitally subtracted from 


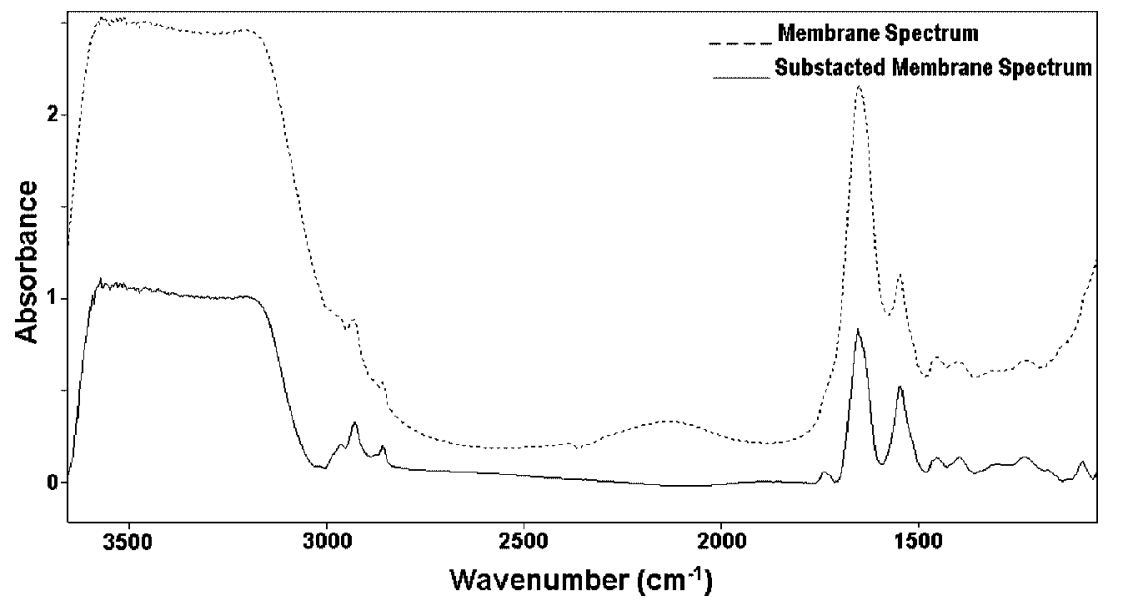

Fig. 1. FTIR spectrum of rat health crude membrane.

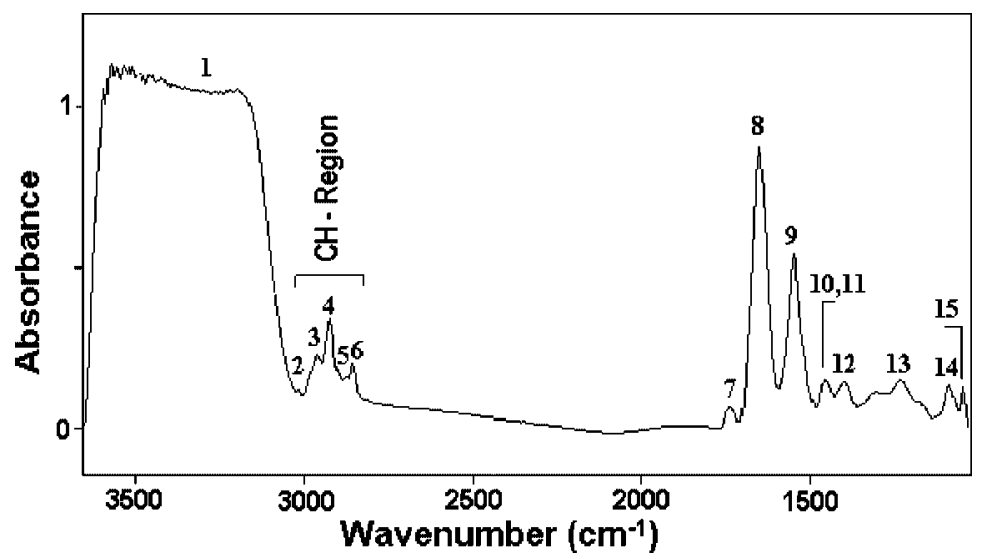

Fig. 2. FTIR spectrum of rat health crude membrane, before and after buffer subtraction.

the membrane spectrum. Figure 1 shows the FTIR spectrum of crude heart membrane for control rat before and after buffer subtraction. As seen from the figure, after water subtraction all bands are clearly seen and a quite flat baseline is observed for further FTIR analysis.

Main absorptions observed in spectra were labeled on Fig. 2 and detailed band assignments were given in Table 1.

As seen in Fig. 2, the infrared spectra of natural membranes are very complex. For this reason in order to display clearly the details of spectral analysis, the spectra were investigated in two regions, the $\mathrm{C}-\mathrm{H}$ stretching $\left(2800-3050 \mathrm{~cm}^{-1}\right)$ and finger print $\left(1000-1800 \mathrm{~cm}^{-1}\right)$ region.

\section{1. $3100-2800 \mathrm{~cm}^{-1}$ region}

Figure 3 shows the mean spectra of diabetic and control rat crude membranes in the $\mathrm{C}-\mathrm{H}$ stretching region at $25^{\circ} \mathrm{C}$. The $\mathrm{CH}_{2}$ antisymmetric and symmetric and $\mathrm{CH}_{3}$ asymmetric stretching bands monitor the lipid acyl chain and the $\mathrm{CH}_{3}$ symmetric stretching bands are mainly due to proteins (Table 1). The changes, which are observed in the frequency, bandwidth and intensity values of these bands between 
Table 1

General band assignment of rat heart crude membrane

\begin{tabular}{|c|c|c|}
\hline \# & Wavenumber $\left(\mathrm{cm}^{-1}\right)$ & Definition of spectral assignment \\
\hline 1 & 3300 & $\begin{array}{l}\text { Amide } \mathrm{A}(\mathrm{N}-\mathrm{H} \text { stretching): proteins } \\
\mathrm{O}-\mathrm{H} \text { stretching vibration }\end{array}$ \\
\hline 2 & 3012 & Olefinic $=\mathrm{CH}$ stretching: unsaturated lipids \\
\hline 3 & 2958 & $\mathrm{CH}_{3}$ asymmetric stretching: lipids \\
\hline 4 & 2924 & $\mathrm{CH}_{2}$ antisymmetric stretching: lipids \\
\hline 5 & 2873 & $\mathrm{CH}_{3}$ asymmetric stretching: mainly proteins, with little contribution from lipids \\
\hline 6 & 2853 & $\mathrm{CH}_{2}$ symmetric stretching vibration: lipids \\
\hline 7 & 1741 & Saturated ester $\mathrm{C}=\mathrm{O}$ stretching: lipid \\
\hline 8 & 1653 & Amide $\mathrm{I}$ ( $80 \%$ protein $\mathrm{C}=\mathrm{O}$ stretching, $10 \%$ protein $\mathrm{N}-\mathrm{H}$ bending, $10 \% \mathrm{C}-\mathrm{N}$ stretching) \\
\hline 9 & 1547 & Amide II ( $60 \%$ protein $\mathrm{N}-\mathrm{H}$ bending, $40 \% \mathrm{C}-\mathrm{N}$ stretching) \\
\hline 10 & 1466 & $\mathrm{CH}_{2}$ scissoring: lipids \\
\hline 11 & 1458 & $\mathrm{CH}_{3}$ scissoring: proteins \\
\hline 12 & 1400 & $\mathrm{COO}^{-}$symmetric stretching: fatty acids \\
\hline 13 & 1232 & $\mathrm{PO}_{2}^{-}$asymmetric stretching: phospholipids \\
\hline 14 & 1080 & $\mathrm{PO}_{2}^{-}$symmetric stretching: phospholipids, $\mathrm{C}-\mathrm{O}$ stretching: oligosaccharides \\
\hline 15 & 1042 & $\mathrm{C}-\mathrm{O}$ stretching: oligosaccharides \\
\hline
\end{tabular}

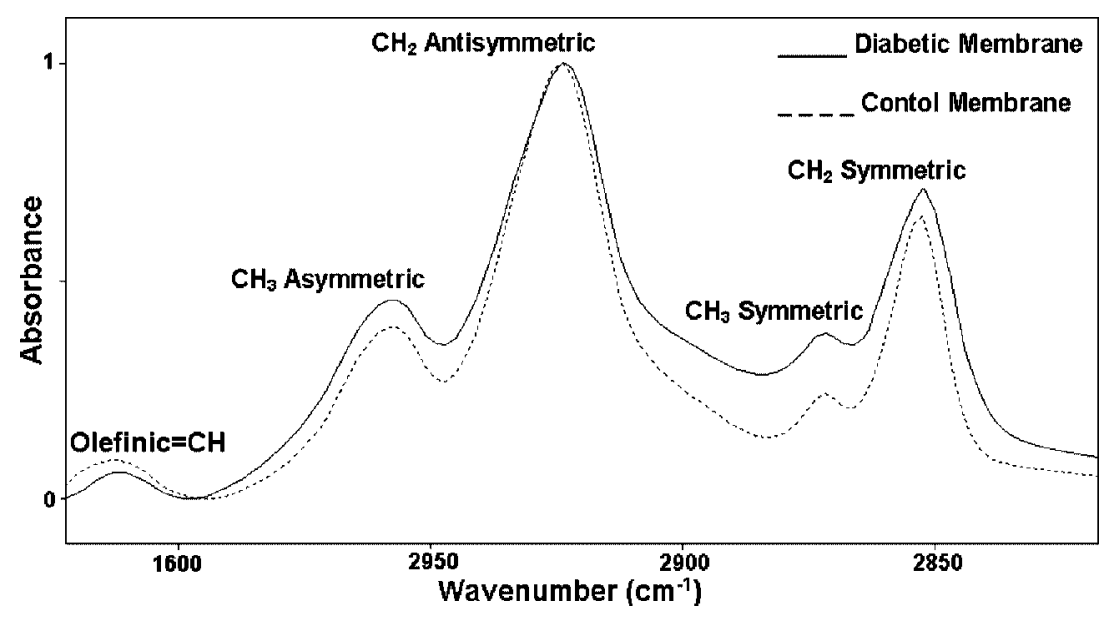

Fig. 3. Mean spectra of the $\mathrm{C}-\mathrm{H}$ stretching region for control and diabetic rat heart crude membranes at $25^{\circ} \mathrm{C}$.

diabetic and control membranes, are used to obtain structural and functional information about the system of interest.

The means of the frequencies of the bands and the intensity values of the olefinic $=\mathrm{CH}$ stretching band in this region were given in Tables 2 and 3, respectively, for control and diabetic membranes. The intensity of the olefinic $=\mathrm{CH}$ band $\left(3012 \mathrm{~cm}^{-1}\right)$ can be used as an index of relative concentration of double bonds in the lipid structure from unsaturated lipids [20]. From the Fig. 3 and Table 3, it is clearly seen that there is a decrease in intensity of olefinic band $(p<0.05)$ in diabetic membranes, indicating a decrease in unsaturated lipid content in these membranes. The reason for this can be the lipid peroxidation, which results in loss of olefinic bonds [18]. In addition, there is a slight frequency shift to lower value for the olefinic $=\mathrm{CH}$ stretching band $(p<0.05)$ in diabetic membranes (Table 2$)$. The shift observed in 
Table 2

The frequency values of the infrared bands in the $\mathrm{C}-\mathrm{H}$ stretching region for control and diabetic spectra at $25^{\circ} \mathrm{C}$

\begin{tabular}{lccc}
\hline Peak & Control $(\bar{\nu})$ & Diabetic $(\bar{\nu})$ & $P$ \\
\hline Olefinic=CH & $3012.96 \pm 0.38$ & $3012.10 \pm 0.42$ & $0.022^{*}(<0.05)$ \\
$\mathrm{CH}_{3}$ asym. & $2957.31 \pm 0.11$ & $2957.10 \pm 0.10$ & 0.6 \\
$\mathrm{CH}_{2}$ antisym. & $2924.38 \pm 0.16$ & $2924.11 \pm 0.7$ & $0.035^{*}(<0.05)$ \\
$\mathrm{CH}_{3}$ sym. & $2872.75 \pm 0.31$ & $2872.45 \pm 0.42$ & 0.3 \\
$\mathrm{CH}_{2}$ sym. & $2853.44 \pm 0.11$ & $2852.75 \pm 0.13$ & $0.001^{*}(<0.05)$ \\
\hline
\end{tabular}

Table 3

Intensity values of the olefinic $=\mathrm{CH}$ band for control and diabetic membranes

\begin{tabular}{cccc}
\hline Temperature & Control membrane $(I)$ & Diabetic membrane $(I)$ & $P$ \\
\hline $25^{\circ} \mathrm{C}$ & $0.082 \pm 0.006$ & $0.057 \pm 0.008$ & $0.015^{*}(<0.05)$ \\
$37^{\circ} \mathrm{C}$ & $0.081 \pm 0.004$ & $0.068 \pm 0.006$ & $0.019^{*}(<0.05)$ \\
\hline
\end{tabular}

olefinic $=\mathrm{CH}$ stretching band may represent the ordering of unsaturated lipids in diabetic membranes [21-24], which can be related with lipid peroxidation. During lipid peroxidation double bonds in the unsaturated acyl chains are broken and the number of trans conformers in the membrane increase.

Table 2 also illustrates the presence of slight shift to lower value of the frequency of the $\mathrm{CH}_{2}$ antisymmetric and symmetric stretching vibrations for diabetic membranes. The band position of the $\mathrm{CH}_{2}$ antisymmetric stretching mode shifts from $2924.38 \pm 0.16$ in control to $2924.11 \pm 0.07(p<0.03)$ in diabetes. Similar shift to lower frequency is observed at diabetic spectra for the $\mathrm{CH}_{2}$ symmetric band position. The $\mathrm{CH}_{2}$ symmetric vibration, shifts from $2853.44 \pm 0.11$ in control to $2852.75 \pm 0.13$ in diabetic membranes $(p<0.05)$. In the previous studies, it was reported that $\mathrm{CH}_{2}$ stretching vibrations depend on the degree of conformational disorder and hence can be used to monitor the average trans/gauche isomerization in the system $[21,22,24,25]$. The present results imply the presence of lower number of gauche conformers, i.e., ordering of lipid bilayer. This result is in agreement with a previous FTIR finding for diabetic platelets [17]. However, in their study, the frequency decrease in $\mathrm{CH}_{2}$ stretching vibrations was interpreted as a decrease in membrane fluidity.

Actually fluidity information are obtained from the bandwidth of the $\mathrm{CH}_{2}$ stretching bands [22,24]. A slight increase in the bandwidth of $\mathrm{CH}_{2}$ antisymmetric vibration mode is observed in diabetic spectra indicating a higher mobility in diabetic membranes (Fig. 2). Similar finding was previous reported in diabetic rat heart and liver tissues [11] and seen in the spectra of other recent study on diabetic platelets [17] although the interpretation of it was not given in the article. In contrast to these findings the other studies on erythrocytes membranes, which used fluorescence spectroscopy, reported a decrease in membrane fluidity [25-27].

Important results can be obtained from the investigation of the $\mathrm{CH}_{2}$ and $\mathrm{CH}_{3}$ symmetric stretching vibrations. An increase in lipid content was obtained from the present study since the signal intensity of $\mathrm{CH}_{2}$ symmetrical mode of lipids increases in diabetic spectra (Fig. 2). This result is in consistent with a previous study, which reported the strong correlation between elevated levels of lipid and the depression in heart function [28]. Since the $\mathrm{CH}_{2}$ symmetric stretching arises mainly from lipids and the $\mathrm{CH}_{3}$ stretching arises mainly from proteins, the intensity ratio of these absorptions gives information about lipid/protein content in the system [12]. Interestingly the results of present study show that in addition to lipid concentration, protein concentration also increases, because there is a decrease in the 
Table 4

Intensity ratio of $\mathrm{CH}_{2}$ to $\mathrm{CH}_{3}$ symmetric stretching vibrations

\begin{tabular}{cccc}
\hline Ratio of band intensities & Control membrane & Diabetic membrane & $P$ \\
\hline $\mathrm{CH}_{2} \mathrm{sym} / \mathrm{CH}_{3} \operatorname{sym}\left(25^{\circ} \mathrm{C}\right)$ & $2.762 \pm 0.160$ & $1.925 \pm 0.126$ & $0.001^{*}(<0.01)$ \\
$\mathrm{CH}_{2} \mathrm{sym} / \mathrm{CH}_{3} \operatorname{sym}\left(37^{\circ} \mathrm{C}\right)$ & $2.750 \pm 0.135$ & $1.875 \pm 0.126$ & $0.001^{*}(<0.01)$ \\
\hline
\end{tabular}

intensity ratio of the $\mathrm{CH}_{2}$ to the $\mathrm{CH}_{3}$ symmetric stretching vibrations. That ratio decreases from $2.762 \pm$ 0.160 in control to $1.925 \pm 0.126$ in diabetic group $(p<0.01)$ (Table 4$)$.

\section{2. $1800-1000 \mathrm{~cm}^{-1}$ region}

The second frequency range, which is under consideration, is $1000-1800 \mathrm{~cm}^{-1}$ region, which is also called finger print region. Fig. 4 shows the mean spectra of control and diabetic crude rat heart membranes, in this region at $25^{\circ} \mathrm{C}$. The spectra were normalized with respect to the Amide I absorption located at $1653 \mathrm{~cm}^{-1}$. As seen from the figure the spectra of the membranes in this region are quite complex consisting of several bands. The mean values of the frequencies of the FTIR bands in this region with standard deviation and $p$ values were listed in Table 5 .

The $\mathrm{C}=\mathrm{O}$ stretching band at $1740 \mathrm{~cm}^{-1}$ monitors the glycerol backbone near the aqueous part of the lipids. This band consists of two overlapping bands which are located at $1742 \mathrm{~cm}^{-1}$ and $1728 \mathrm{~cm}^{-1}$. The high frequency absorption represents free $\mathrm{C}=\mathrm{O}$ group, while low absorption arises from hydrogen bounded $\mathrm{C}=\mathrm{O}$ group [29]. As seen from Table 5 the frequency of this band decreases from $1742.15 \pm 0.62$ in control to $1741.08 \pm 0.33$ in diabetic spectra $(p<0.01)$. It implies the reorientation of the lipid head groupswith a decrease in free carbonyl groups, which are the results of a hydrogen bonding formation [22, 24,30].

The findings of higher lipid content in diabetic membranes based on the analysis of the $\mathrm{C}-\mathrm{H}$ stretching bands are supported by the intensity increase of lipid ester band at $1740 \mathrm{~cm}^{-1}$ which originates from the ester $\mathrm{C}=\mathrm{O}$ group and the $\mathrm{PO}_{2}^{-}$asymmetric stretching vibrations of lipid head groups at $1240 \mathrm{~cm}^{-1}$ (Fig. 4). Actually, the $\mathrm{PO}_{2}^{-}$asymmetric stretching vibration arises mainly from nucleic acids with little contribution of phospholipids [31]. However in the present study since nucleic acids are excluded from the system in sample preparation of crude membranes, the $1240 \mathrm{~cm}^{-1}$ band arises from phospholipids.

The strong amide I band in the FTIR spectra has been widely used for determination of the secondary structure of proteins [32]. This band is due to in plane $\mathrm{C}=\mathrm{O}$ stretching vibration weakly coupled with $\mathrm{C}-\mathrm{N}$ stretching and in plane $\mathrm{N}-\mathrm{H}$ bending. Since the peak maximum of the amide I band occurs at different frequencies for various type of secondary structures, the discrete types of secondary structure in membrane proteins can be identified by the frequencies of these maxima in their FTIR spectra [20]. The components of that amide I band are due to amide group segments in the $\beta$-sheets, the $\alpha$-helices, the turns and anti-parallel $\beta$-sheets showed at approximately $1630 \mathrm{~cm}^{-1}, 1655 \mathrm{~cm}^{-1}, 1670 \mathrm{~cm}^{-1}$ and $1682 \mathrm{~cm}^{-1}$, respectively [32]. The random coils are detected at a frequency of approximately $1640 \mathrm{~cm}^{-1}$ [33].

In the present study the frequency of the amide I band in control membranes appear at around $1653 \mathrm{~cm}^{-1}$ indicating that protein segments with the $\alpha$-helical conformation are predominant. It is seen from Table 5 that, the frequency of that band shifts from $1653.23 \pm 0.59$ in control to $1651.73 \pm 0.48$ in diabetic membranes $(p<0.05)$. A shift to lower frequency was also observed in diabetic membranes for amide II absorption band $(p<0.05)$. These shifts reflect altered protein profiles in diabetic samples compared to those in control ones. The similar shifts to lower values of amide I and amide II absorption bands were previously reported in the human platelet membranes [17]. Moreover, in diabetic spectra (Fig. 4) a new band at $1639 \mathrm{~cm}^{-1}$ appears, reporting an increase in the number of random coil at the 


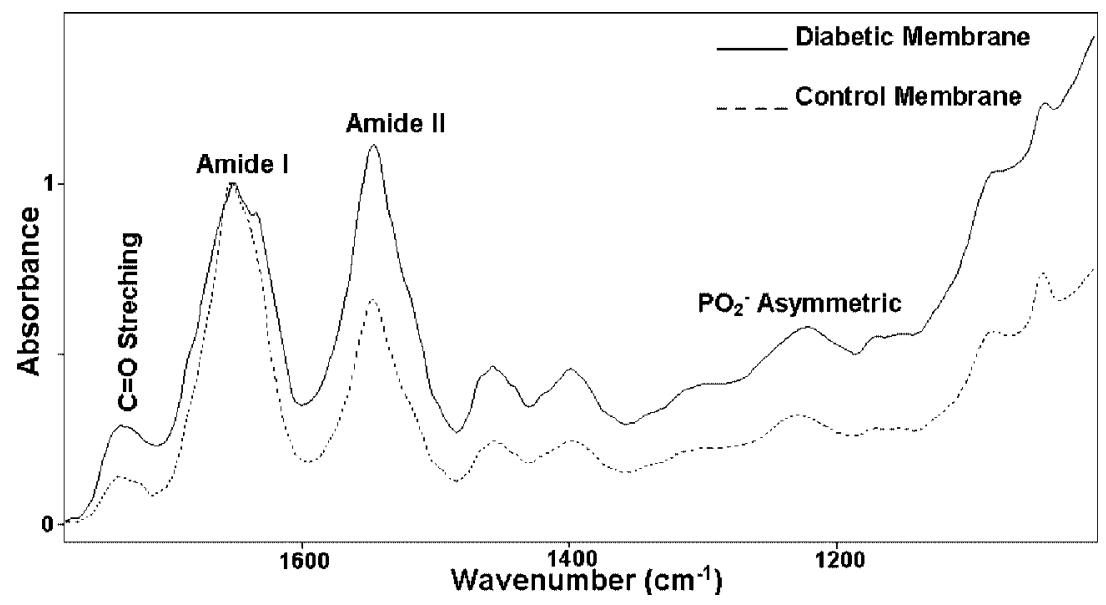

Fig. 4. Mean spectra for control and diabetic rat heart crude heart membranes in $1000-1800 \mathrm{~cm}^{-1}$ region at $25^{\circ} \mathrm{C}$.

Table 5

The frequency values of the infrared bands in $1000-1800 \mathrm{~cm}^{-1}$ region for control and diabetic spectra at $25^{\circ} \mathrm{C}$

\begin{tabular}{lccc}
\hline Peak & Control $(\bar{\nu})$ & Diabetic $(\bar{\nu})$ & $P$ \\
\hline C=O stretch. & $1742.15 \pm 0.62$ & $1741.08 \pm 0.33$ & $0.006^{*}<0.01$ \\
Amide I & $1653.23 \pm 0.59$ & $1651.73 \pm 0.48$ & $0.036^{*}<0.05$ \\
Amide II & $1546.36 \pm 0.44$ & $1544.80 \pm 0.34$ & $0.003^{*}<0.01$ \\
$\mathrm{PO}_{2}^{-}$asym. & $1231.23 \pm 0.59$ & $1630.73 \pm 0.48$ & $0.004^{*}<0.01$ \\
\hline
\end{tabular}

expense of $\alpha$-helices. This is together with a decrease in the ratio of amide I to amide II (Fig. 4) may correspond to denaturation of some proteins in diabetic membranes.

Changes in the hydration state of the head group of phospholipids are investigated by the analysis of the frequency of the $\mathrm{PO}_{2}^{-}$antisymmetric double bond stretching. As reported in the literature, the frequency around $1200 \mathrm{~cm}^{-1}$ indicating hydrogen bounded phosphate groups, and at $1240 \mathrm{~cm}^{-1}$ indicating free phosphate groups [34]. It is clearly seen from Fig. 4 and Table 5 that, the frequency of this band shifts to lower value $(p<0.05)$ for diabetic membrane indicating an increase in hydrogen bonding either with the oxygen of the phosphate head group or with its aqueous environment [35].

From the mean spectra of diabetic and control membranes, illustrated in Fig. 4 one can easily observe that, the intensity of the band at $1042 \mathrm{~cm}^{-1}$, which is due to oligosaccharides, increases. This indicates an increase in oligosaccharides concentration in diabetic membranes [17].

\section{Acknowledgement}

This work was supported by research grants from State Planning Organization of Turkey and METU research Fund.

\section{References}

[1] A.G. Tahiliani and J.H. Mcneill, Diabetes-induced abnormalities in the myocardium, Life Sci. 38 (1986), 959-974. 
[2] F.S. Fein and E.H. Sonnenblick, Diabetic cardiomyopathy, Prog. Cardiovas. Dis. 27 (1985), 255-270.

[3] S.W. Schaffer, Cardiomyopathy associated with noninsulin-dependent diabetes, Mol. Cell Biochem. 107 (1991), 1-20.

[4] K. Pyorla, M. Laasko and M. Uusitupa, Diabetes and atherosclerosis: an epidemiological view, Diabetes Metabolism Reviews 3 (1987), 463-524.

[5] N.S. Dhalla, G.N. Pierce, I.R. Innes and R.E. Beamish, Pathogenesis of cardiac dysfunction in diabetes mellitus, Can. J. Cardiol. 1 (1985), 26.

[6] J.H. McNeill and B. Rodrigues, The diabetic heart: metabolic causes for the development of cardiomyopathy, Cardiovasc. Res. 26 (1996), 913-922.

[7] S.S. Ahmed, G. Jaferi, R.M. Narang and T.J. Regan, Preclinical abnormality of left ventricular function in diabetes mellitus, Am. Heart J. 89 (1975), 153-158.

[8] S.K. Jain and S.N. Levine, Eleveted lipid peroxidation and vitamin E-Quinone levels in heart ventricles of streptozotocintreated diabetic rats, Free Rad. Biol. Medicine 18 (1995), 337-341.

[9] P. Dixit and R. Ekstrom, Decreased breaking strength of diabetic rat bone and its improvement by insulin treatment, Calcif. Tiss. Int. 32 (1980), 195-199.

[10] K.A. Athanasiou, J.G. Fleischli, J. Bosma, T.J. Laughlin, C.F. Zhu, C.M. Agrawal and L.A. Lavery, Effects of diabetes mellitus on the biochemical properties of human ankle cartilage, Clin. Orthop. Rel. Res. 368 (1999), 182-189.

[11] B. Moeckel, M.H. Hou, E.A. Salvati and P.M. Pellicci, Total hip arthroplasty in patients with diabetes mellitus, J. Arthroplasty 8 (1993), 279-284.

[12] F. Severcan, N. Toyran, N. Kaptan and B. Turan, Fourier transform infrared study of the effect of diabetes on rat liver and heart tissues in the C-H region, Talanta 53 (2000), 55-59.

[13] R.D. Sauerheber, C.E. Khun and P.A. Hyslop, Membrane structural/functional properties of adipocytes from normal and streptozotocin-diabetic rats, Diabetes 33 (1984), 258-265.

[14] T. Kamada and S. Otsuji, Lower levels of erythrocyte membrane fluidity in diabetic patients, Diabetes 32 (1983), 585-591.

[15] I. Waczuliková, L. Šikurová, J. Čársky, L. Štrbová and B. Krahulec, Decreased fluidity of isolated erythrocyte membranes in type 1 and type 2 diabetes. The effect of resorcylidene aminoguanidine, Gen. Physiol. Biophys. 19 (2000), 381-392.

[16] P.D. Winocour, C. Watala, D.W. Perry and R.L. Kinlough-Rathbone, Thromb. Haemost. 75 (1992), 577.

[17] K. Liu, R. Bose and H.H. Mantsch, Infrared spectroscopic study of diabetic platelets, Vib. Spec. 860 (2002), 1-6.

[18] R.H. Sill, D.J. Moore and R. Mendelson, Erythrocyte peroxidation: Quantitation by Fourier transform infrared spectroscopy, Analyt. Biochem. 218 (1994), 118-123.

[19] Y. Öztürk, V.M. Altan and N. Y1ldızoğlu-Arı, Effect of experimental diabetes and insulin on smooth muscle functions, Pharmacol. Rev. 48 (1997), 1-44.

[20] H. Takahashi, W. French and P.T.T. Wong, Alteration in hepatic lipids and proteins by chronic ethanol intake: A highpressure Fourier transform infrared spectroscopy study on alcoholic liver disease in the rat, Alcoholism: Clin. Exp. Res. 15(2) (1991), 219-223.

[21] H.H. Mantsch, Biological application of Fourier transform infrared spectroscopy: A study of phase transitions in biomembranes, J. Mol. Struct. 113 (1984), 201-212.

[22] F. Lopez-Garcia, J. Villalain and J.C. Gomez-Fernandez, Infrared spectroscopic studies of the interaction of diacylglycerols with phosphatidylcerol, phosphatidylserin in the presence of calcium, Biochim. Biophys. Acta 1169 (1993), $264-272$.

[23] F. Severcan, Vitamin E decreases the order of the phospholipid model membranes in the gel phase: An FTIR study, Biosc. Reports 17 (1997), 231-235.

[24] H. Boyar and F. Severcan, Oestrogen-phospholipid membrane interactions: an FTIR study, J. Molec. Struct. 408/409 (1997), 269-272.

[25] M.E. Bizeau, J.M. Salano and R. Jefrey, Menhaden oil feeding increases lypolysis without changing plasma membrane order in isolated rat adipocytes, Nutrition Research 20(11) (2000), 1633-1644.

[26] C. Watala and P.D. Winocourt, The relasionship of chemical modification of membrane proteins and plasma lipoproteins to reduced membrane fluidity of erythrocytes from diabetic subject, Eur. J. Clin. Chem. Clin. Biochem. 30 (1992), 513-519.

[27] H. Cardilorous, S. Muller, N. Zeghari, M. Donner, P. Droiun and O. Aeigler, Decreased erythrocyte membrane fluidity in poorly controlled IDDM, Diabetes Care 18 (1995), 549-551.

[28] J.H. McNeill, Role of elevated lipids in diabetic cardiomyopathy, Diabetes Res. Clin. Prac. 31 (1996), 67-71.

[29] M. Jackson and H.H. Mantsch, Biomembrane structure from FT-IR spectroscopy, Spectrochim. Acta Rev. 15 (1993), $53-$ 69.

[30] N. Kazanc1, N. Toyran, I.P. Haris and F. Severcan, Vitamin $\mathrm{D}_{2}$ at high and low concentrations exert opposing effects on molecular order and dynamics of dipalmitoyl phosphatidylcholine membranes, Spectroscopy 15 (2001), 47-55.

[31] J. Wang, C. Chi, S. Lin and Y. Chern, Conformational changes in gastric carcinoma cell membrane protein correlated to cell viability after treatment with adamantyl maleimide, Anticancer Res. 17 (1997), 3473-3478.

[32] P.I. Haris and F. Severcan, FTIR spectroscopic characterization of protein structure in aqueous and non-aqueous media, J. Molecular Catalysis: B (Enzymatic) 7 (1999), 207-221. 
[33] C. Cardin, S.W. French and P. Wong, Alteration in molecular structure of cytoskeleton proteins in griseofulvin-treated mouse liver: A pressure tuning infrared spectroscopy study, Exp. Molec. Pathol. 55 (1991), 170-179.

[34] R.A. Dluhy, D.G. Cameron, H.H. Mantsch and R. Mendelsohn, Fourier transform infrared spectroscopic studies of the effect of calcium ions on phosphatidylcerin, Biochemistry 22 (1983), 6318-6325.

[35] C.R. Flach, J.W. Brauner and R. Mendelson, Calcium ion interactions with insoluble phospholipid monolayer films at the A/W interface: External reflection-absorption infrared studies, Biophys J. 65(5) (1993), 1994-2001. 


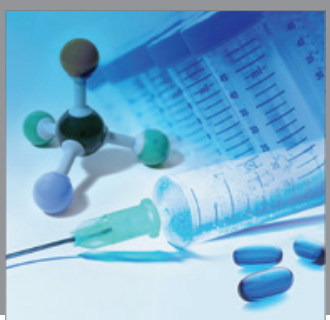

International Journal of

Medicinal Chemistry

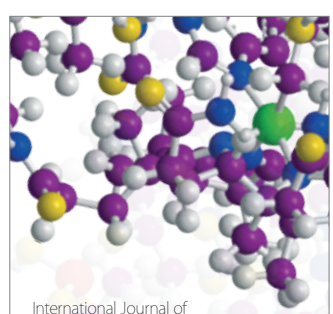

Carbohydrate Chemistry

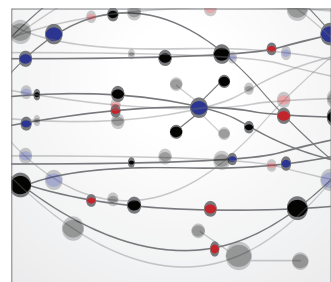

The Scientific World Journal
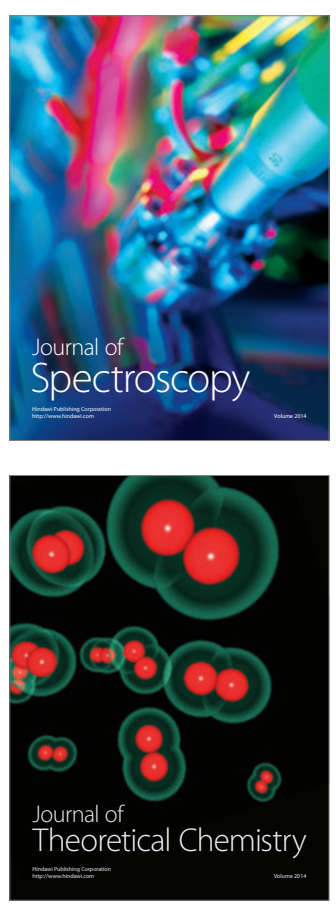
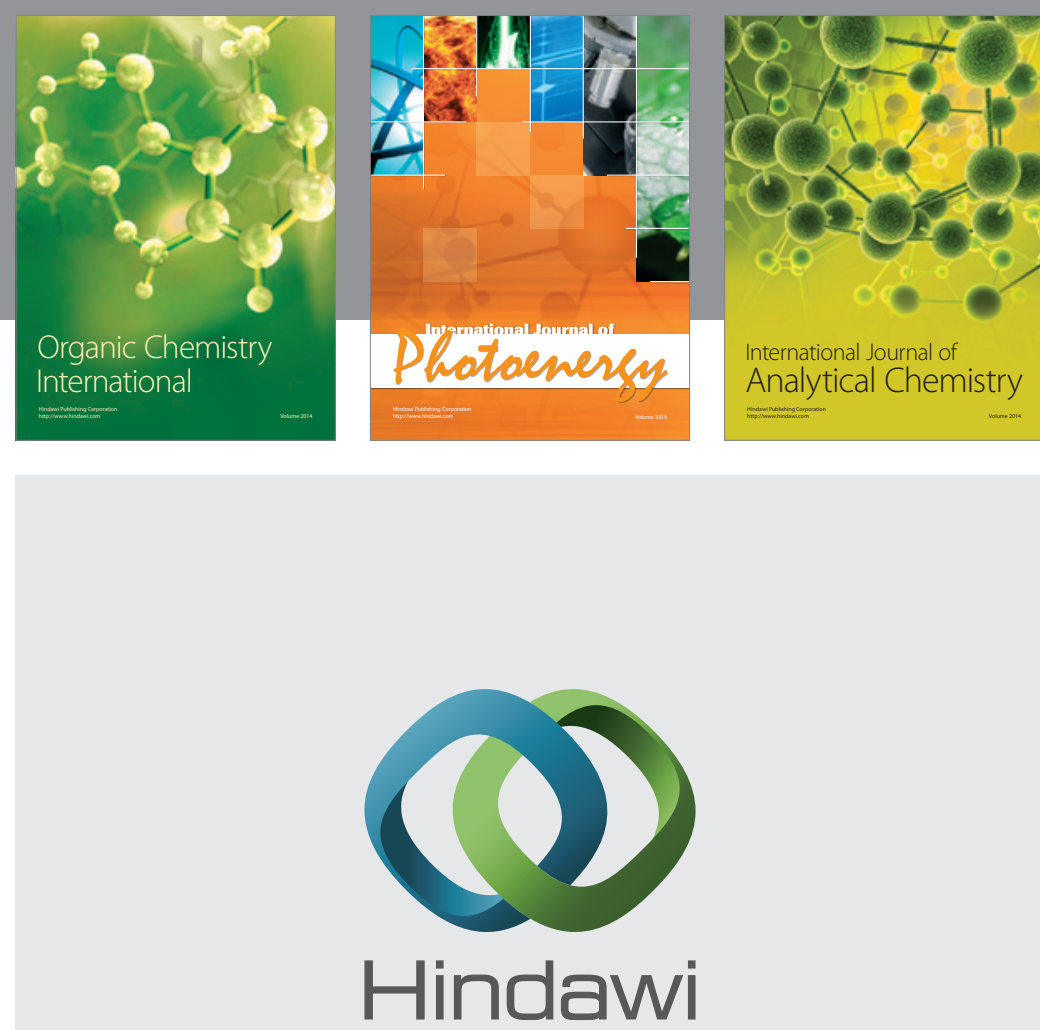

Submit your manuscripts at

http://www.hindawi.com
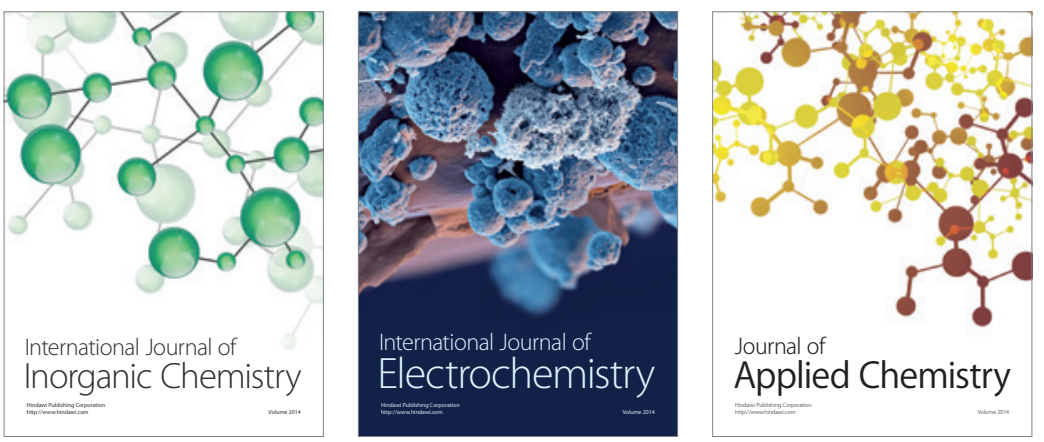

Journal of

Applied Chemistry
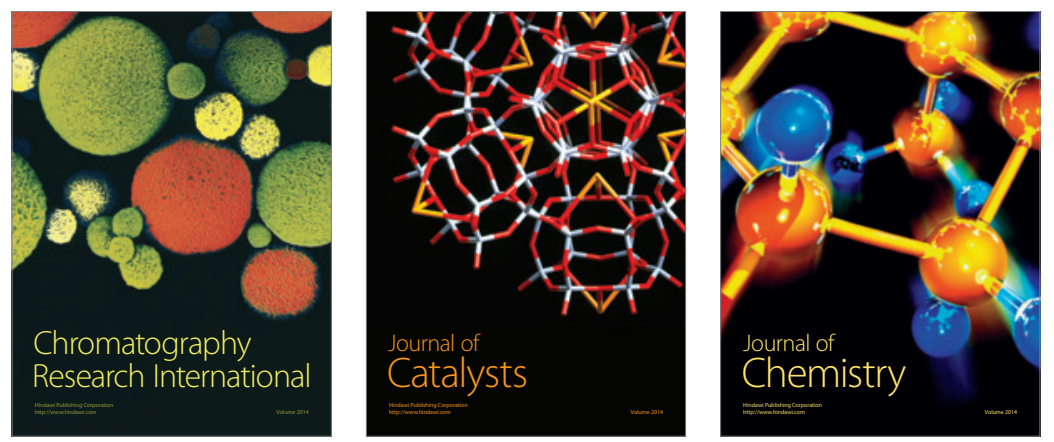
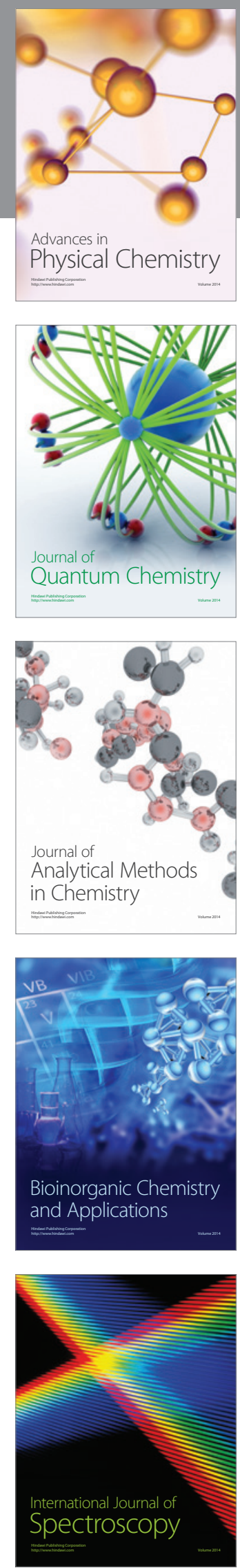